\title{
A novel $\beta$-glucosidase in Uromyces fabae: feast or fight?
}

\begin{abstract}
Efficient nutrient mobilization is a key element for biotrophic plant parasites such as the rust fungi. In the course of a cDNA library screen for elements involved in sugar utilization in Uromyces fabae, we identified a sequence with homology to $\beta$-glucosidases. Full-length genomic and cDNA clones of the gene, termed $B G L 1$, were isolated and sequenced. The $B G L 1$ gene comprises 3,372 nucleotides, including nine introns. The open reading frame encompasses 2,532 bases and codes for a polypeptide of 843 amino acids with an apparent molecular mass of $92.4 \mathrm{kDa}$. Analysis of the polypeptide revealed a potential secretion signal, indicating an extracellular localization of mature BGL1p $(89.8 \mathrm{kDa})$. BGL1 seems to be expressed in all stages of growth, including haustoria, the feeding structures of rust fungi. In the course of immunolocalization studies, the gene product BGL1p was localized in the periphery of intercellular hyphae and haustoria. On the basis of sequence homology, the $B G L 1$ gene was identified as a fungal $\beta$-glucosidase.
\end{abstract}

Keywords Uromyces fabae $\beta$-Glucosidase $\cdot$ Fungal nutrition $\cdot$ Fungal defense

\section{Introduction}

Like a large number of plant parasitic fungi, rust fungi are obligate biotrophic pathogens which depend on their living host plant for nutrient mobilization and reproduction. In this obligate parasitic relationship, the host

Communicated by U. Kück

A. C. Haerter · R. T. Voegele $(\square)$

Phytopathologie, Fachbereich Biologie, Universität Konstanz, Universitätsstrasse 10, 78457 Konstanz, Germany

E mail: Ralf.Voegele@uni konstanz.de

Tel.: + 497531882356

Fax: +497531883035 plant becomes a source for sugars, amino acids and other nutrients (Szabo and Bushnell 2001). Obligate biotrophs live in close contact with their host plant and, in exchange for nutrients and information, they differentiate special structures, so-called haustoria (Hahn and Mendgen 2001). Because we are interested in elements involved in sugar utilization, we screened a cDNA library for genes encoding proteins participating in sugar resourcing. Among several other enzymes acting in nutrient mobilization, we found a $\beta$-glucosidase.

Members of the large and diverse group of $O$-glycosyl hydrolases [EC 3.2.1.-] cleave the $O$-linked glycosidic bond between two ore more carbohydrates, or between a carbohydrate and a non-carbohydrate moiety. Classification according to sequence similarity shows that glycosyl hydrolases can be grouped into more than 90 different families (Henrissat and Davies 1997; Coutinho and Henrissat 1999). $\beta$-Glucosidases (EC 3.2.1.21; $\beta$ D-glucoside glucohydrolase), a subgroup of $O$-glycosyl hydrolases, occur widely in prokaryotes and eukaryotes and are implicated in several important biological processes (Bhatia et al. 2002). In fungi and bacteria, for example, $\beta$-glucosidases are involved in cellulose and cellobiose catabolism as part of the cellulase complex and thus play a role in the process of biomass conversion (Leah et al. 1995). Specific plant $\beta$-glucosidases are involved in defense reactions against pathogens via the process of cyanogenesis, whereby $\mathrm{HCN}$ and other toxic compounds are released upon hydrolysis of cyanogenic glucosides (Poulton 1990; Osbourn 1996). A number of phytopathogenic fungi use $\beta$-glucosidases to overcome plant defense mechanisms (Morrissey and Osbourn 1999). They are able to detoxify saponins, preformed fungitoxic compounds, by deglycosylation (Bowyer et al. 1995; Osbourn et al. 1995; Morrissey et al. 2000).

Here, we describe the identification and characterization of a $\beta$-glucosidase gene, $B G L 1$, and the corresponding gene product, BGLlp, of the rust fungus, Uromyces fabae. This is the first description of a $\beta$-glucosidase from a biotrophic plant parasite. Our results indicate the role of BGLlp in cellobiose degradation, 
but do not rule out a role for BGL1p in the suppression of host defense responses.

\section{Materials and methods}

Cultivation of plant and rust fungus

Cultivation of Vicia faba var. Con Amore, inoculation with $U$. fabae uredospores, germination of spores and growth of in vitro grown infection structures were performed as described by Deising et al. (1991) and Hahn and Mendgen (1997).

\section{Nucleic acid manipulations}

The isolation of RNA from infected leaves, infection structures and isolated haustoria and the extraction of total DNA from germi nated spores were performed according to Hahn and Mendgen (1997). The haustorium specific cDNA and genomic DNA libraries were constructed as described by Hahn and Mendgen (1997). The screening of libraries and other nucleic acid manipulations were done using standard molecular biology techniques (Sambrook and Russell 2001).

Non radioactive hybridization experiments were performed according to Engler Blum et al. (1993). Genomic Southern and Northern hybridizations were carried out using homologous probes at hybridization temperatures between $65^{\circ} \mathrm{C}$ and $68^{\circ} \mathrm{C}$. Signal detection was performed using anti digoxigenin AP Fab fragments [with CSPD (Roche Diagnostics, Mannheim, Germany) as substrate] and autoradiography.

\section{DNA sequencing and phylogenetic analysis}

Sequencing was performed using the Big Dye terminator cycle sequencing ready reaction mix ver. 2.0 (PE Applied Biosystems, Foster City, Calif.) on an ABI 377 HT automated sequencer (GATC, Konstanz, Germany). Sequencing data were evaluated and analyzed using Chromas 2.13 (Technelysium, Helensvale, Australia) and the DNAstar ver. 5.3 package (DNAstar, Madison, Wis.). Homology searches were performed using the BLAST algorithm (Altschul et al. 1997). For phylogenetic analysis, sequences were aligned using the ClustalW algorithm in the MegAlign program (DNAstar) for border alignment. Sequences were then aligned manually using MUST (Philippe 1993). Analysis was performed using the PUZZLE (Strimmer and von Haeseler 1997), MRBAYES (Huelsenbeck and Ronquist 2001) and MEGA2.1 (Kumar et al. 2001) programs.

\section{Plasmid constructions}

Plasmid pDR 195::BGL1 was constructed by digestion of the full length cDNA clone $\lambda \mathrm{gt} 10:: B G L 1$ with NotI and ligation into plasmid pDR195 (Rentsch et al. 1995). The resulting plasmid was used for the transformation of Saccharomyces cerevisiae strain 23344c (Marini et al. 2000). Yeast transformation was done as described by Elble (1992)

Plasmid pET28a::BGL $M$ was constructed by introducing un ique EcoRI and $X h o I$ restriction sites into $B G L 1$ by means of PCR. The PCR fragment $B G L M$ (nucleotides 9671,877 in the pub lished sequence excluding introns) was cloned into the vector pET28a(+) (Novagen, Madison, Wis.), yielding a His tagged BGL1p fusion protein.

Expression of His tagged BGL1p fusion protein and antibody generation

Over expression of the fusion protein encoded by the plasmid pET28a::BGL $M$ was done using Escherichia coli strain BL21(DE3)
(Novagen) and induction with isopropyl $\beta$ D thiogalactoside (Studier and Moffatt 1986). Purification of the fusion protein was performed using immobilized metal ion affinity chromatography under denaturing conditions (The QIAexpressionist; Qiagen, Hil den, Germany), according to the manufacturer's protocol. Anti bodies were generated by repeated injection of a rabbit with purified fusion protein together with Freund's adjuvant. Serum S768 for BGL1p M was purified in a two step procedure, according to Voegele et al. (2001). S768 was adsorbed first to immobilized INVn2p ( $\mathrm{N}$ terminal part of an invertase of $U$. fabae) to remove undesired antibodies, including anti His tag antibodies. The flow through was collected and applied to a column containing immo bilized BGL1p M fusion protein for positive adsorption. Adsorbed BGL1p M specific antibodies were eluted with $50 \mathrm{mM}$ glycine $/ \mathrm{HCl}$ $(\mathrm{pH} 2.2)$ and immediately neutralized.

\section{Immunoblot analysis}

Protein preparations were separated on $7.5 \%$ SDS PAGE gels (Laemmli 1970). The immunoblot analysis was conducted as de scribed by Sohn et al. (2000). As primary antibody, purified rabbit anti BGL1p serum (S768p) was used. Visualization was performed with peroxidase coupled goat anti rabbit secondary antibody (Sigma Aldrich Chemie, Mannheim, Germany) and ECL Western blot detection reagent (Amersham Bioscience, Freiburg, Germany). To obtain protein preparations for immunoblot analysis, protein isolation from rust infected leaves ( 8 days post infection) and non infected leaves was performed according to Römer et al. (2000). The haustorial protein composition was analyzed using isolated haustoria (Hahn and Mendgen 1992). Protein was precipitated from filtered supernatants and from pellets of $S$. cerevisiae $23344 \mathrm{c}$ pDR 195::BGL1 cultures (at $72 \mathrm{~h}$ ) by treatment with $40 \%$ trichlo roacetic acid (TCA).

For deglycosylation, protein samples were denatured at $95{ }^{\circ} \mathrm{C}$ for $10 \mathrm{~min}$. Samples were incubated with 100 units endoglycosidase $\mathrm{H}_{\mathrm{f}} / \mu \mathrm{l}$ (New England Biolabs, Frankfurt am Main, Germany) in $5 \mathrm{mM}$ sodium citrate $(\mathrm{pH} 5.5)$ at $37^{\circ} \mathrm{C}$ for $3 \mathrm{~h}$.

\section{Assay of BGL1p function}

The activity of BGL1p heterologously expressed in S. cerevisiae 23344 c with different substrates was determined using synthetic complete (SC) plates with the following carbon sources at $2 \%$ $(\mathrm{w} / \mathrm{v}): \mathrm{D}(+)$ cellobiose, salicin, methyl $\beta$ D glycopyranoside or $p$ nitrophenyl $\alpha$ D glucopyranoside. All substrates were purchased from Sigma Aldrich Chemie. Plates were incubated for 3 weeks at $30{ }^{\circ} \mathrm{C}$. To quantify the BGL1p effect, $23344 \mathrm{c}$ cells harboring the transgene or control vector were grown in SC liquid medium containing either $\mathrm{D}(+)$ glucose or $\mathrm{D}(+)$ cellobiose at $2 \%(\mathrm{w} / \mathrm{v})$.

\section{Immunocytochemistry}

Sections for light microscopy were prepared from infected leaves at 7 days post infection, as described by Voegele et al. (2001). To reduce non specific binding, the sections were incubated for $10 \mathrm{~min}$ in blocking buffer [10 mM TBS $(10 \mathrm{mM}$ Tris $\mathrm{HCl}, 150 \mathrm{mM} \mathrm{NaCl}$, $\mathrm{pH} 7.4$ ), $5 \%$ bovine serum albumin (BSA), $5 \%$ goat serum]. The sections were then treated three times with incubation buffer (10 mM TBS, pH 7.4, 1\% BSA), and incubated with purified anti BGL1p antibody [1:100 dilution in $0.375 \times$ incubation buffer, $0.125 \times$ blocking buffer, $0.25 \times$ yeast buffer (yeast in $75 \%$ TBS, $0.25 \times$ bean leaf buffer ( $V$. faba in TBS)] for $2 \mathrm{~h}$. To detect non specific binding, pre immune serum was used as a control. After washing three times with TBS, sections were incubated with secondary antibody (cyanin 3 conjugated goat anti rabbit; Rockland, Gil bertsville, Pa.), diluted 1:400 with TBS, for $30 \mathrm{~min}$ at $20^{\circ} \mathrm{C}$. Samples were examined with a Zeiss Axioplan 2 microscope equipped with a $\times 100$ Plan Neofluar, using Nomarski differential 
interference contrast or epifluorescence (filters BP 490, FT 510, LP 565). Images were taken with an AxioCam high resolution digital camera combined with AXIOVISION software (Zeiss) and superimposed using Photoshop ver. 6.0 (Adobe Systems, Mountain View, Calif.).

Sequence data

Nucleotide sequence data reported in this paper were deposited in the European Molecular Biology Laboratory database under accession number AJ575269.

\section{Results}

Analysis of the $B G L 1$ gene

In the course of screening a haustorium-specific $U$. fabae $\lambda$-gt10 cDNA library, a clone was found which contained part of the coding region for a putative $\beta$-glucosidase. This partial cDNA fragment was used to screen the $\lambda$-gt10 cDNA library to isolate a full-length $B G L 1$ clone. The $B G L 1 \mathrm{cDNA}$ has a single open reading frame of $2,532 \mathrm{bp}$ and encodes a polypeptide of 843 amino acids with a calculated molecular mass of $92.4 \mathrm{kDa}$. An in silico screen for potential localization signals gave evidence for a potential secretion signal. However, further analysis of the potential signal peptide of BGL1p provided contradictory results. The Neural Networks algorithm did not find any indication for a secretion signal (Nielsen et al. 1997), while the Hidden Markov Model algorithm indicated the existence of a signal peptide (Nielsen and Krogh 1998). Prediction of the signal peptide cleavage site suggested a 25 -amino-acid signal peptide, with A26 as the N-terminal amino acid of the mature protein $\left(\mathrm{M}_{1}\right.$ KTPLGIGSTAAVLYILSNI$\left.\mathrm{SHVQL}_{25} / \mathrm{A}_{26}\right)$. The calculated molecular mass of the mature polypeptide is $89.8 \mathrm{kDa}$.

Based on its amino acid sequence, BGL1p was analyzed for domain architecture via SMART (Schultz et al. 1998; Letunic et al. 2002). BGL1p belongs to glycoside hydrolase family 3 , which currently accommodates enzymes of fungal, bacterial and plant origin, with a broad range of substrate specificities. Members of this family are characterized as globular proteins with a twodomain structure. This organization pattern is also reflected in BGL1p. Amino acids 101-381 at the $\mathrm{N}$-terminus could form the $\mathrm{N}$-terminal domain. A second, C-terminal domain is found at amino acids 450 698. The latter domain is thought to be involved in catalysis and may be involved in binding $\beta$-glucan.

Glycoside hydrolase family 3 has three distinct $N$-glycosylation sites and diverse $O$-glycosylation sites. The BGL1p of $U$. fabae has three predicted $N$-glycosylation sites and four potential $O$-glycosylation sites.

The genomic BGL1 sequence comprises 3,372 bp. Comparison of the genomic and cDNA sequences of $B G L 1$ indicated the presence of nine introns, varying in size between $63 \mathrm{bp}$ and $145 \mathrm{bp}$ (average size $93.3 \mathrm{bp}$ ). The average GC content was found to be $45.2 \%$.
Comparison of amino acid sequences

Databases at the National Center for Biotechnology Information (USA) were searched for sequences similar to the deduced amino acid sequence of $B G L 1$ (Altschul et al. 1997). Phylogenetic analysis revealed significant levels of similarity to a variety of $\beta$-glucosidases. The highest homology scores were found for a $\beta$-glucosidase from Phanerochaete chrysosporium (BAB85988, 46\% identity; Fig. 1). Homology was also found to $\beta$-glucosidases from Ajellomyces capsulatus (AAA86880), Aspergillus aculeatus (P48825), A. kawachii (BAA19913), A. niger (CAB75696) and Coccidioides posadasii (AAB67972) which participate in cellulolytic degradation. A remarkably high similarity was found to avenacinases from Botryotinia fuckeliana (CAB61489), Gaeumannomyces graminis (AAB09777) and Talaromyces emersonii (AAM94393) and a tomatinase from Septoria lycopersici (AAB08445; Fig. 1). These are enzymes involved in the detoxification of plant defense compounds.

\section{Copy number of the $B G L 1$ gene}

To estimate the number of copies of the BGL1 gene, genomic DNA of $U$. fabae was digested with eight different restriction enzymes and then hybridized with a 744-bp, digoxigenin-labeled probe. Hybridization was carried out at $68^{\circ} \mathrm{C}$ and subsequent washes were performed under high-stringency conditions. A single band was found in six of the eight digests (Fig. 2). Only the $P v u \mathrm{II}$ and the HindIII digests revealed two hybridization signals (Fig. 2). Both restriction enzymes cut once within the sequence of the probe. Southern blot analysis therefore clearly indicates that $B G L 1$ is a single-copy gene.

\section{Analysis of $B G L 1$ expression}

The expression of $B G L 1$ during rust development was analyzed by Northern hybridization. Figure 3 shows that $B G L 1$ seems to be expressed in all early stages of growth (infection structures formed in vitro; lanes 1-6). A $B G L 1$ transcript is also present in haustoria (lane 7) and to a lesser extend in infected leaves (lane 8). This effect is due to the fact that, in infected leaves, fungal mRNA represents only a minor fraction of the total mRNA. The negative control with RNA from non-infected leaves (lane 9) showed no signal. The observed expression pattern was clearly distinct from a class of genes of $U$. fabae that were characterized as in planta-induced genes (Hahn and Mendgen 1997).

\section{Analysis of BGL1p localization}

Immunofluorescence microscopy of infected leaves, using the purified antibody $\mathrm{S} 768 \mathrm{p}$, revealed labeling of nearly all fungal structures (Fig. 4). Controls with 


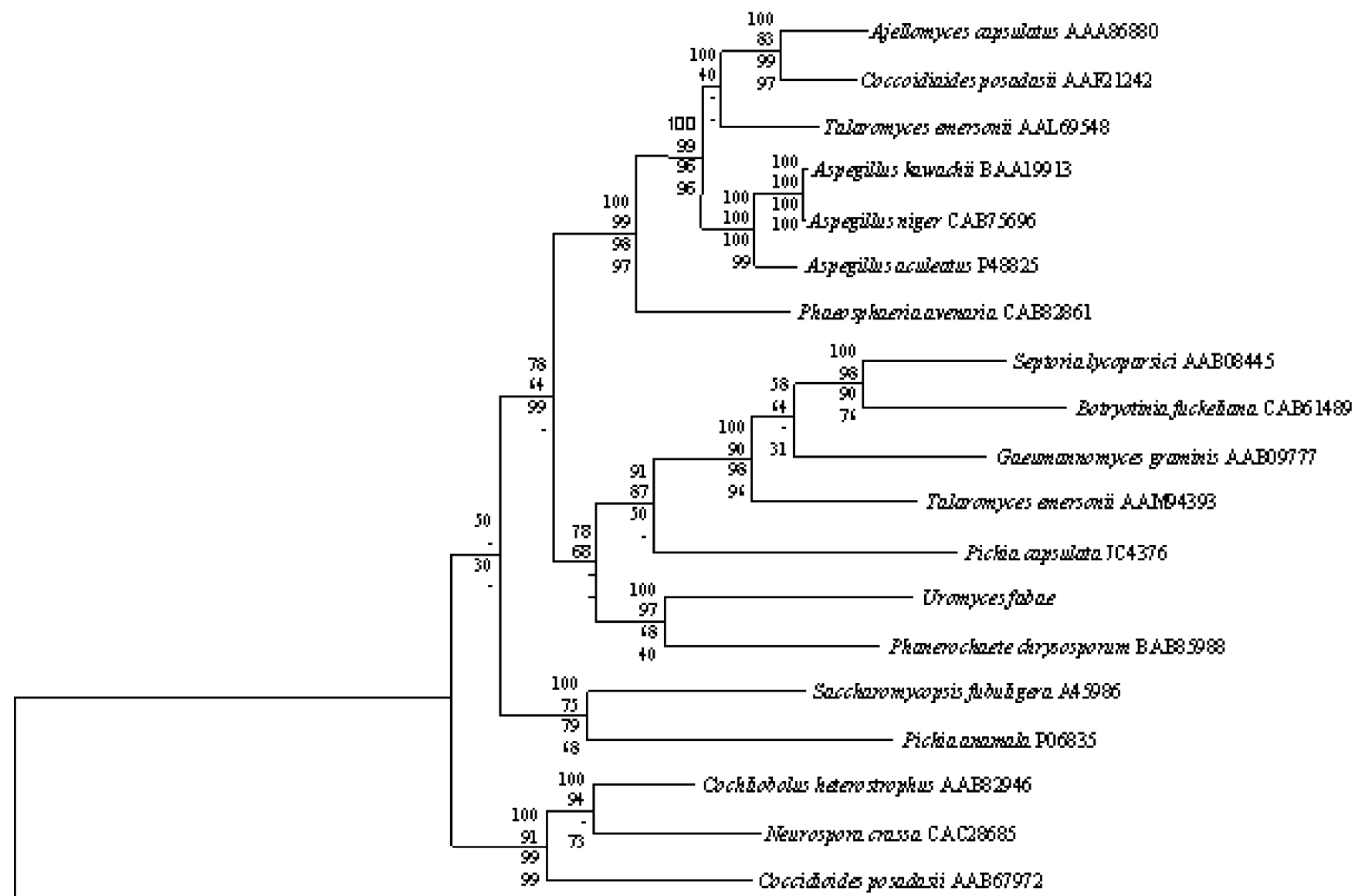

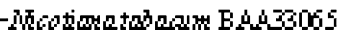

Fig. 1 Homology of BGLlp to other fungal $\beta$ glucosidases. The maximum likelihood tree is shown. Bootstrap values for Bayesian inference of phylogeny, maximum likelihood, distance based neighbor joining and maximum parsimony methods (from top to bottom) are indicated at the corresponding branch points. Sequences are identified by species name and accession numbers

pre-immune serum did not show any labeling of infected leaf tissue (data not shown). Strong specific labeling was found in the periphery of the extracellular hyphae and haustoria. The pattern of protein localization was consistent with results from the expression analysis of $B G L 1$. The peripheral localization was taken as further evidence that BGL1p is an enzyme active in the extracellular space. However, the resolution of light microscopy does not allow a specific localization beyond this level.

\section{Expression of BGL1p in Saccharomyces cerevisiae}

To characterize BGL1p at a biochemical level, a full-length $B G L 1$ cDNA clone was ligated into a yeast expression vector. The resulting plasmid,
pDR195::BGL1, was used for transformation of $S$. cerevisiae strain 23344 c. BGL1p could only be detected in samples after precipitation with TCA (Fig. 5), indicating that the level of expression is weak, even from the fairly strong PMA1 promoter. No signal was observed in cells transformed with vector pDR195. TCA-treated supernatants of $23344 \mathrm{c}$ pDR195::BGL1 cultures also revealed no signal in Western blot analyses. This result shows that BGL1p is not liberated into the medium, but remains tightly associated with the cellular fraction.

To elucidate the substrate specificity of BGL1p, yeast transformants containing pDR195::BGL1 or pDR195 were grown on different substrates. In contrast to the transformants containing only plasmid pDR195, yeast transformants containing pDR195::BGL1 showed a growth advantage on $\mathrm{D}(+)$-cellobiose as substrate (Fig. 6). No growth difference was observed using $\mathrm{D}(+)$ glucose as a carbon source (data not shown). This result indicated that BGL1p might play a role in cellulose/ cellobiose degradation and provided further evidence for the secretion of BGL1p, even in the heterologous system. 
Fig. 2A, B $B G L 1$ is a single copy gene. A Schematic representation of the $B G L 1$ sequence. The position of each cleavage site for the restriction enzymes and the position of the probe are indicated. $<$ B Total DNA of Uromyces fabae was prepared from germinated spores and digested with HindIII, PvuII, BamHI, EcoRI, PstI, SacI, ScaI and SspI. Southern blot analysis using a $B G L 1$ specific cDNA probe produced single bands in all cases, except $P v u I I$ and HindIII. For PvuII and HindIII, two bands were obtained due to probe internal $P v u I I$ and HindIII sites. Numbers on the right give molecular weight marker sizes (in kilobases)

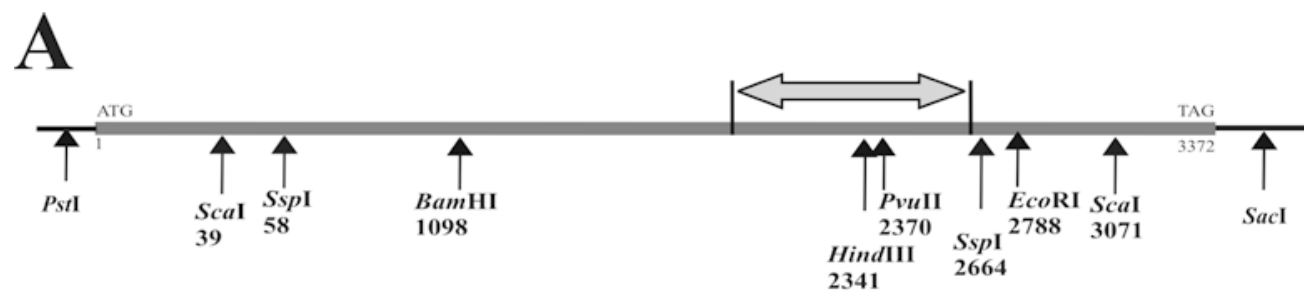

B

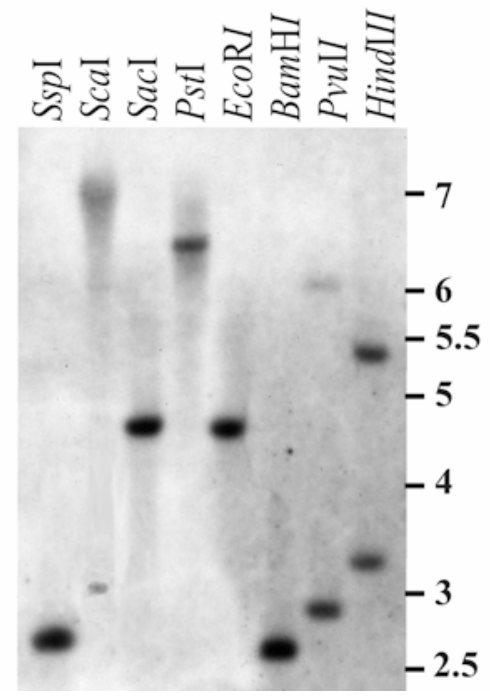

Characterization of the $U$. fabae BGL1p in infected plants and haustoria

The apparent molecular mass of BGL1p prepared from infected leaves and isolated haustoria was determined by Western blot analysis to be $120 \mathrm{kDa}$ (Fig. 7). Deglycosylation analysis indicated that about $30 \mathrm{kDa}$ of the molecular mass of BGL1p can be attributed to $N$-linked carbohydrates. The molecular mass of deglycosylated BGL1p corresponds well to the theoretically calculated molecular mass of $89.8 \mathrm{kDa}$. We conclude that BGL1p passes the $U$. fabae secretory machinery, where it is glycosylated and secreted afterwards.

\section{Discussion}

We are interested in understanding the molecular mechanisms involved in nutrient mobilization for biotrophic plant parasites. As part of this work, several genes of transporters and enzymes and their protein products have been characterized (Voegele and Mendgen 2003). Here, we describe a $\beta$-glucosidase possibly involved in substrate provision or the suppression of host defense responses. The gene, BGL1, was isolated from the biotrophic rust fungus, $U$. fabae. The gene product, BGL1p, was localized immunocytochemically and functionally characterized.

In the present study, we determined cDNA and genomic sequences of a $\beta$-glucosidase of $U$. fabae. The $\beta$-glucosidase gene of $U$. fabae is interrupted by nine introns, with an average size of $93.3 \mathrm{bp}$, a normal length for $U$. fabae congruent with previously published results (Struck et al. 1996; Sohn et al. 2000; Voegele et al. 2001). Like in all $U$. fabae genes analyzed so far, introns followed the GT/AG rule (Hahn, unpublished data; Saxonov et al. 2000).

Genomic Southern hybridization revealed no indication of multiple copies of the BGL1 gene in the rust genome. This result was supported by the observation that several independently isolated partial $B G L 1 \mathrm{cDNA}$ clones from haustoria showed no sequence variation. $B G L 1$ seems to be a low-copy-number gene, like most of the published U. fabae genes (Hahn and Mendgen 1997).

The BGL1p protein consists of 843 amino acids and has an apparent molecular mass of $92.4 \mathrm{kDa}$. However, the apparent molecular mass of BGL1p from infected plants, haustoria and transgenic $S$. cerevisiae was experimentally determined to be about $120 \mathrm{kDa}$ (Figs. 5, 7). Deglycosylation analysis indicated that approximately $30 \mathrm{kDa}$ of the $U$. fabae BGL1p mass can be attributed to $N$-linked carbohydrates. BGL1p has three possible $N$-glycosylation sites conforming to the general rule Asn- $X$-Thr/Ser, in which $X$ is not a proline. The molecular mass of deglycosylated BGL1p is about $90 \mathrm{kDa}$ and agrees well with the predicted molecular mass of BGL1p, which was calculated to be $92.4 \mathrm{kDa}$ for the complete protein and $89.8 \mathrm{kDa}$ for the most likely mature form (signal sequence cleavage between amino acids 25/26). The fact that BGLlp is glycosylated both in the homologous expression system (Fig. 7, blocks $1+/ 3+)$ and in the heterologous expression 
A

B
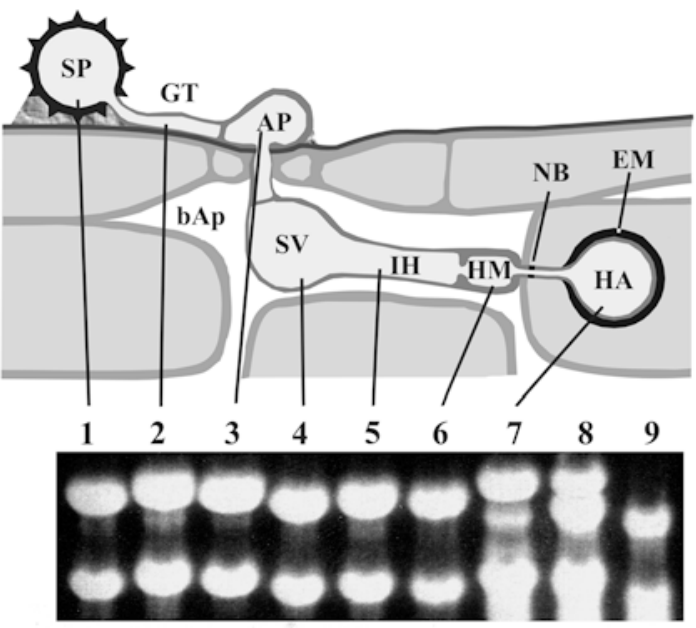

C

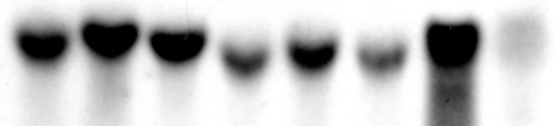

[kb]
Fig. 3A C $B G L 1$ transcripts are found in early stages of growth, in intercellular hyphae and in haustoria. A Schematic representa tion of rust infection structures. B Ethidium bromide stained denaturing agarose gel (loading control). C Northern blot of the gel depicted in B. Lane 1 Uredospore $(S P)$, lane 2 germ tube $(G T)$ after $4 \mathrm{~h}$ germination, lanes 36 in vitro infection structures harvested at different stages [lane 3 appressorium $(A P)$ stage $(6 \mathrm{~h})$, lane 4 substomatal vesicle $(S V)$ stage $(12 \mathrm{~h})$, lane 5 infection hyphae $(I H)$ stage $(18 \mathrm{~h})$, lane 6 haustorial mother cell $(H M)$ stage $(21 \mathrm{~h})]$, lane 7 isolated haustoria $(H A)$, lane 8 infected leaves, lane 9 non infected leaves. $b A p$ Bulk apoplast, $N B$ neckband, $E M$ extrahaus torial matrix. The number on the right gives an estimated size (in kilobases)

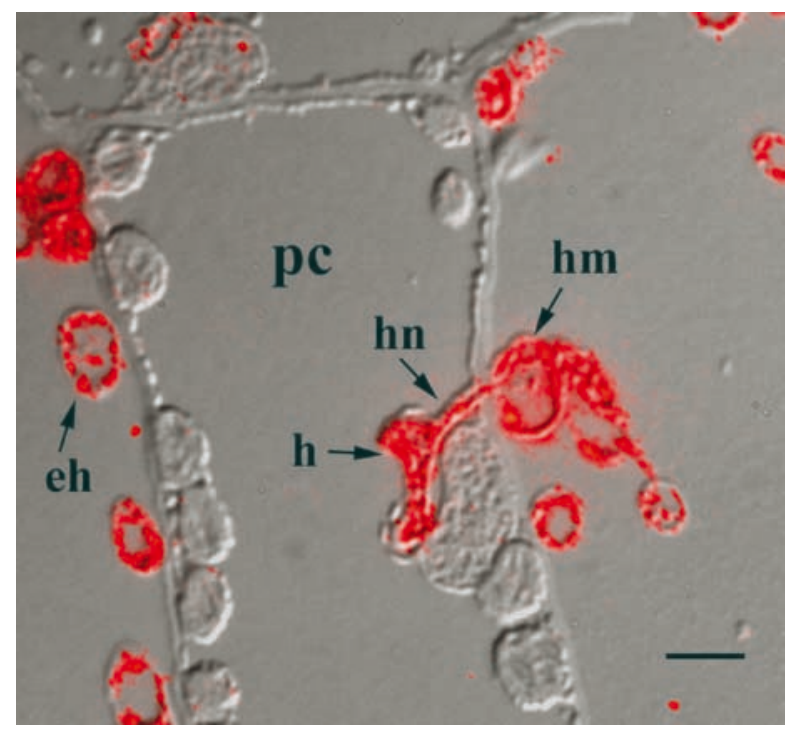

Fig. 4 Localization of BGL1p in different fungal structures. These superimposed Nomarski differential interference contrast and fluorescence images depict a haustorium and several intercellular hyphae. The labeling of BGL1p with S768p resulted in strong fluorescence signals in the periphery of the extracellular hyphae and in the haustoria. $h$ Haustorium, $h n$ haustorial neck, $h m$ haustorial mother cell, $p c$ plant cell, eh extracellular hyphae. Bar $4 \mu \mathrm{m}$

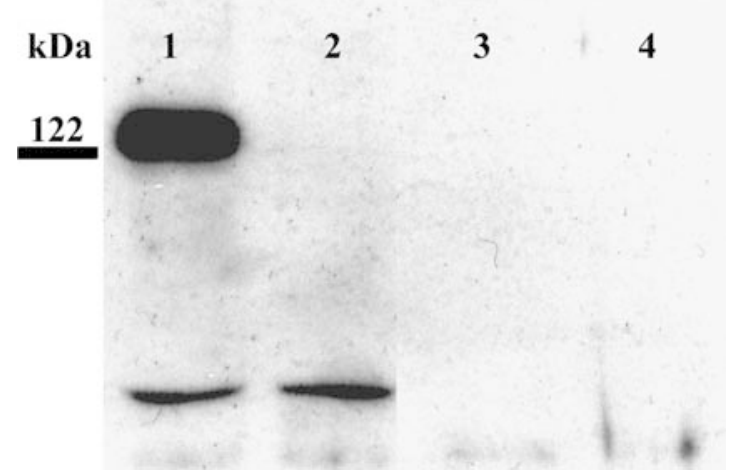

Fig. 5 Western blot analysis of BGL1p expressed in Saccharomyces cerevisiae. Lanes 1, 2 trichloroacetic acid (TCA) precipitate of $S$. cerevisiae cells transformed with pDR195::BGL1 (lane 1) or pDR195 (negative control; lane 2). Lane 3 TCA treated super natants of $S$. cerevisiae pDR195::BGL1, lane $4 S$. cerevisiae pDR195 (negative control). Antibody dilution was 1:10,000. The number on the left indicates the molecular mass standard

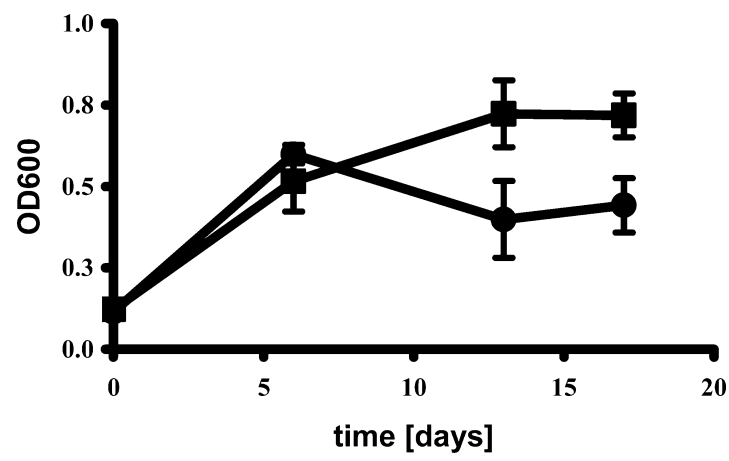

Fig. 6 BGL1p is able to cleave cellobiose. A growth comparison is presented for $S$. cerevisiae 23344c containing pDR195::BGL1 (black squares) or pDR195 (black circles) in synthetic complete medium containing $2 \% \mathrm{D}(+)$ cellobiose as sole carbon source. The graph depicts the mean of triplicate experiments \pm SE

system (Fig. 7, block $2+$ ) is evidence for the extracellular localization of BGL1p. These data, together with the immunolocalization, clearly indicate that BGLlp is secreted. However, the fact that BGL1p is not detectable in the supernatant of transgenic yeast might indicate an association with the cell wall, at least in the heterologous expression system. Furthermore, there is no indication for additional post-translational modification other than $N$-glycosylation and signal sequence cleavage.

Analysis of the deduced amino acid sequence of $B G L 1$ showed that the protein is a member of a large class of proteins known as family $3 \beta$-glucosidases. Family $3 \beta$-glucosidases contain enzymes that hydrolyze $\beta$-D-glucose or $\beta$-L-xylose residues from a wide variety of substrates. For example, the $\beta$-glucosidase from $P$. chrysosporium is involved in cellulose degradation $(\mathrm{Li}$ and Renganathan 1998). The $\beta$-glucosidase of C. posadasii plays a morphogenetic role in the parasitic cycle and the $\beta$-glucosidases from G. graminis, Septoria lycopersici and $B$. cinerea hydrolyze plant saponins. Despite 
Fig. 7 Detection of BGL1p by immunoblot analysis. Block 1 Total protein of infected leaves, block 2 total protein of $S$. cerevisiae pDR195::BGL1, block 3 isolated haustoria, block 4 total protein of non infected leaves. + Untreated samples, - deglycosylated protein samples. Antibody dilution was 1:10,000. Numbers on the left indicate molecular mass standards

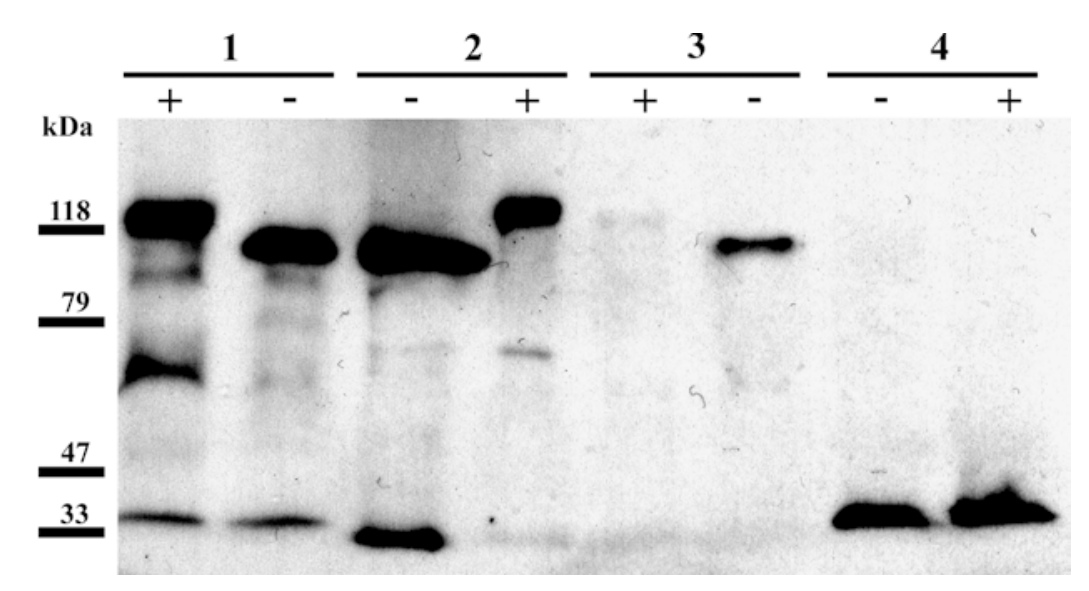

the high degree of conservation among these enzymes, they can be very specific for particular substrates (Morrissey et al. 2000).

The $\beta$-glucosidase from $P$. chrysosporium exhibited the highest level of homology (46\% identity) to the BGL1p from $U$. fabae ( $\mathrm{Li}$ and Renganathan 1998). Further homology was found to the $\beta$-glucosidases of several cellulolytic Aspergillus species. Aspergillus species, especially $A$. niger, are by far the most efficient producers of $\beta$-glucosidases among the microorganisms investigated (Dan et al. 2000).

Rust fungi need to penetrate the host cell wall and form haustoria in the host cells. A study by Heiler et al. (1993) showed that cellulolytic enzymes might be involved in a coordinated manner during the penetration of host cell walls by rust fungi. It could be hypothesized that the $\beta$-glucosidase of $U$. fabae participates in the cellulolytic degradation of the plant cell walls. To gain further information about the function of BGL1p in cellulolytic degradation, yeast cells transformed with pDR195::BGL1 were cultivated on plates containing different carbon sources. When cellobiose was offered as substrate, the transformed yeast cells seemed to be able to cleave the substrate. $B G L 1$ transformants had a growth advantage, compared with cells transformed with the vector only. Therefore, cellobiose has to be considered a potential substrate for the BGL1p of $U$. fabae. BGL1p could either play a role in cellulose degradation for nutrient supply or participate in the penetration process necessary to invade the host cell.

The expression pattern of $B G L 1$ was examined to gain further insights into the role(s) of BGL1p. BGL1 seems to be expressed in germinated spores, in the infection structures produced on artificial membranes, in intercellular hyphae and also in haustoria, which play a major role in nutrient assimilation for the parasite (Fig. 3C). The expression of BGL1 in early infection structures might be taken as evidence against a role in nutrient supply. No hexose transporter is present in these stages (Voegele et al. 2001). However, the expression of BGL1 in haustoria, together with the immunolocalization of BGL1p in the periphery of haustoria
(Fig. 4), indicates that BGL1p could be able to supply glucose substrate for the hexose transporter.

The early expression of $B G L 1$ supports the idea that the onset of $B G L 1$ transcription coincides with the first contact between fungus and plant. This expression pattern in turn could be expected for an enzyme involved either in the degradation of plant cell walls or in the degradation of anti-fungal components.

There is remarkable homology to $\beta$-glucosidases from five phytopathogenic fungi (B. fuckeliana, $G$. graminis, $P$. avenaria, $S$. lycopersici, and $T$. emersonii), which are responsible for the detoxification of saponins (Fig. 1). Saponins are glycosylated triterpenoid, steroid, or steroidal alkaloid molecules found in a large number of plants (Morrissey et al. 2000). Broad bean ( $V$. faba) contains some of these defense molecules, termed vicine [2,6-diamino-5-( $\beta$-D-glucopyranosyloxy)4-pyrimidinone] and convicine [6-amino-2-hydroxy-5( $\beta$-D-glucopyranosyloxy)-4-pyrimidinone]. These pyrimidine glucosides are known to have an inhibitory effect on the in vitro growth of $V$. faba fungal pathogens, like Ascochyta fabae and B. cinerea (Bjerg et al. 1984), and are postulated to play a role in the defense of foliar diseases. It remains to be shown whether BGL1p also plays a role in the detoxification of these or related compounds.

Acknowledgements This work was carried out in the laboratory of Kurt W. Mendgen, to whom we are indebted for continuous sup port. We are grateful to Heinz Vahlenkamp for expert technical assistance with immunocytology and Simone Högg for assistance with the phylogenetic analysis.

\section{References}

Altschul SF, Madden TL, Schaffer AA, Zhang J, Zhang Z, Miller W, Lipman DJ (1997) Gapped BLAST and PSI BLAST: a new generation of protein database search programs. Nucleic Acids Res 25:3389 3402

Bhatia Y, Mishra S, Bisaria VS (2002) Microbial beta glucosidases: cloning, properties, and applications. Crit Rev Biotechnol 22:375 407

Bjerg B, Heide M, Knudsen JCN, Sorensen H (1984) Inhibitory ef fects of convicine, vicine and dopa from Vicia faba on the in vitro growth rates of fungal pathogens. J Plant Dis Prot 91:483 487 
Bowyer P, Clarke BR, Lunness P, Daniels MJ, Osbourn AE (1995) Host range of a plant pathogenic fungus determined by a saponin detoxifying enzyme. Science 267:371 374

Coutinho PM, Henrissat B (1999) Carbohydrate active enzymes: an integrated database approach. In: Gilbert HJ, Davies G, Henrissat B, Svensson B (eds) Recent advances in carbohydrate bioengineering. Royal Society of Chemistry, Cambridge, pp 312

Dan S, Marton I, Dekel M, Bravdo BA, He S, Withers SG, Sho seyov O (2000) Cloning, expression, characterization, and nucleophile identification of family 3, Aspergillus niger beta glucosidase. J Biol Chem 275:4973 4980

Deising H, Jungblut PR, Mendgen K (1991) Differentiation related proteins of the broad bean rust fungus Uromyces viciae fabae, as revealed by high resolution two dimensional polyacrylamide gel electrophoresis. Arch Microbiol 155:191 198

Elble R (1992) A simple and efficient procedure for transformation of yeasts. Biotechniques 13:18 20

Engler Blum G, Meier M, Frank J, Muller GA (1993) Reduction of background problems in nonradioactive Northern and South ern blot analyses enables higher sensitivity than ${ }^{32} \mathrm{P}$ based hybridizations. Anal Biochem 210:235 244

Hahn M, Mendgen K (1992) Isolation by ConA binding of haus toria from different rust fungi and comparison of their surface qualities. Protoplasma 170:95 103

Hahn M, Mendgen K (1997) Characterization of in planta induced rust genes isolated from a haustorium specific cDNA library. Mol Plant Microbe Interact 10:427 437

Hahn M, Mendgen K (2001) Signal and nutrient exchange at biotrophic plant fungus interfaces. Curr Opin Plant Biol 4:322 327

Heiler S, Mendgen K, Deising H (1993) Cellulolytic enzymes of the obligated biotrophic rust fungus Uromyces viciae fabae are regulated differentiation specifically. Mycol Res 97:77 85

Henrissat B, Davies G (1997) Structural and sequence based clas sification of glycoside hydrolases. Curr Opin Struct Biol 7:637 644

Huelsenbeck JP, Ronquist F (2001) MRBAYES: Bayesian infer ence of phylogenetic trees. Bioinformatics 17:754 755

Kumar S, Tamura K, Jakobsen IB, Nei M (2001) MEGA2: molecular evolutionary genetics analysis software. Bioinfor matics 17:1244 1245

Laemmli UK (1970) Cleavage of structural proteins during the assembly of the head of bacteriophage T4. Nature 227:680 685

Leah R, Kigel J, Svendsen I, Mundy J (1995) Biochemical and molecular characterization of a barley seed beta glucosidase. J Biol Chem 270:15789 15797

Letunic I, Goodstadt L, Dickens NJ, Doerks T, Schultz J, Mott R, Ciccarelli F, Copley RR, Ponting CP, Bork P (2002) Recent improvements to the SMART domain based sequence anno tation resource. Nucleic Acids Res 30:242 244

Li B, Renganathan V (1998) Gene cloning and characterization of a novel cellulose binding beta glucosidase from Phanerochaete chrysosporium. Appl Environ Microbiol 64:2748 2754

Marini AM, Springael JY, Frommer WB, Andre B (2000) Cross talk between ammonium transporters in yeast and interference by the soybean SAT1 protein. Mol Microbiol 35:378 385

Morrissey JP, Osbourn AE (1999) Fungal resistance to plant antibiotics as a mechanism of pathogenesis. Microbiol Mol Biol Rev 63:708 724
Morrissey JP, Wubben JP, Osbourn AE (2000) Stagonospora ave nae secretes multiple enzymes that hydrolyze oat leaf saponins. Mol Plant Microbe Interact 13:1041 1052

Nielsen H, Krogh A (1998) Prediction of signal peptides and signal anchors by a hidden Markov model. Proc Int Conf Intell Syst Mol Biol 6:122 130

Nielsen H, Engelbrecht J, Brunak S, Heijne G von (1997) A neural network method for identification of prokaryotic and eukary otic signal peptides and prediction of their cleavage sites. Int $\mathrm{J}$ Neural Syst 8:581 599

Osbourn A (1996) Preformed antimicrobial compounds and plant defense against fungal attack. Plant Cell 8:1821 1831

Osbourn A, Bowyer P, Lunness P, Clarke B, Daniels M (1995) Fungal pathogens of oat roots and tomato leaves employ clo sely related enzymes to detoxify different host plant saponins. Mol Plant Microbe Interact 8:971 978

Philippe H (1993) MUST, a computer package of management utilities for sequences and trees. Nucleic Acids Res 21:5264 5272

Poulton JE (1990) Cyanogenesis in plants. Plant Physiol 94:401 405

Rentsch D, Laloi M, Rouhara I, Schmelzer E, Delrot S, Frommer WB (1995) NTRl encodes a high affinity oligopeptide trans porter in Arabidopsis. FEBS Lett 370:264 268

Römer S, Fraser PD, Kiano JW, Shipton CA, Misawa N, Schuch W, Bramley PM (2000) Elevation of the provitamin A content of transgenic tomato plants. Nat Biotechnol 18:666 669

Sambrook J, Russell DW (2001) Molecular cloning: a laboratory manual, 3rd edn. Cold Spring Harbor Laboratory Press, Cold Spring Harbor, N.Y.

Saxonov S, Daizadeh I, Fedorov A, Gilbert W (2000) EID: the exon intron database an exhaustive database of protein cod ing intron containing genes. Nucleic Acids Res 28:185 190

Schultz J, Milpetz F, Bork P, Ponting CP (1998) SMART, a simple modular architecture research tool: identification of signaling domains. Proc Natl Acad Sci USA 95:5857 5864

Sohn J, Voegele RT, Mendgen K, Hahn M (2000) High level activation of vitamin $\mathrm{B} 1$ biosynthesis genes in haustoria of the rust fungus Uromyces fabae. Mol Plant Microbe Interact $13: 629636$

Strimmer K, Haeseler A von (1997) Likelihood mapping: a simple method to visualize phylogenetic content of a sequence align ment. Proc Natl Acad Sci USA 94:6815 6819

Struck C, Hahn M, Mendgen K (1996) Plasma membrane $\mathrm{H}^{+}$ ATPase activity in spores, germ tubes, and haustoria of the rust fungus Uromyces viciae fabae. Fungal Genet Biol 20:30 35

Studier FW, Moffatt BA (1986) Use of bacteriophage T7 RNA polymerase to direct selective high level expression of cloned genes. J Mol Biol 189:113 130

Szabo LJ, Bushnell WR (2001) Hidden robbers: the role of fungal haustoria in parasitism of plants. Proc Natl Acad Sci USA 98:7654 7655

Voegele RT, Mendgen K (2003) Rust haustoria: nutrient uptake and beyond. New Phytol 159:93 100

Voegele RT, Struck C, Hahn M, Mendgen K (2001) The role of haustoria in sugar supply during infection of broad bean by the rust fungus Uromyces fabae. Proc Natl Acad Sci USA 98:8133 8138 